\title{
Exogenous and endogenous opioid-induced pain hypersensitivity in different rat strains
}

\author{
Emilie Laboureyras $\mathrm{MSc}^{1}$, Frédéric Aubrun $\mathrm{PhD}^{2,3}$, Maud Monsaingeon MD¹, Jean-Benoît Corcuff MD PhD ${ }^{1}$, \\ Jean-Paul Laulin $\mathrm{PhD}^{1}$, Guy Simonnet $\mathrm{PhD}^{1}$
}

\author{
E Laboureyras, F Aubrun, M Monsaingeon, J-B Corcuff, J-P Laulin, \\ $\mathrm{G}$ Simonnet. Exogenous and endogenous opioid-induced pain \\ hypersensitivity in different rat strains. Pain Res Manag \\ 2014;19(4):191-197.
}

BACKGROUND: Opioid-induced hyperalgesia $(\mathrm{OIH})$ is a recognized complication of opioid use that may facilitate the development of exaggerated postoperative pain.

OBJECTIVE: To examine the role of genetic factors on OIH by comparing four rat strains. Because the authors previously reported that the endogenous opioids released during non-nociceptive environmental stress induce latent pain sensitization, genetic and environmental factor interactions were also evaluated.

METHODS: First, the propensity of Sprague Dawley, Wistar, Lewis and Fischer rats to develop OIH following single or repeated fentanyl exposures was compared by measuring the nociceptive threshold using the paw pressure vocalization test. Second, Sprague Dawley and Fischer rats were exposed to a series of three non-nociceptive environmental stress sessions to evaluate the ability of endogenous opioids to enhance hyperalgesia associated with a carrageenan-induced hind-paw inflammation test performed two weeks later.

RESULTS: Sprague Dawley, Wistar and Lewis rats exhibited OIH, although differences were observed. OIH was not observed in Fischer rats. Inflammatory hyperalgesia enhancement induced through previous stress in Sprague Dawley rats was not observed in Fischer rats.

CONCLUSIONS: The pain level not only reflects nociceptive inputs but also depends on both the history and genetic factors of the individual. Genetic and environmental models may provide new insights into the mechanisms that underlie individual differences observed in postoperative pain.

Key Words: Genetic factors; Individual history; Pain hypersensitivity; Rat strains

$\mathrm{O}$ pioids are the most effective painkillers in humans. The use of opioids for the treatment of chronic pain has increased dramatically over the past decade. Although these drugs provide considerable benefits in terms of pain reduction, a growing number of experimental and clinical studies have reported that opioid therapy may render patients more sensitive to nociception via the delayed activation of pronociceptive pathways resulting in an increased risk of developing persistent pain (1-9). This enhanced pain sensitivity has been referred to as opioid-induced hyperalgesia $(\mathrm{OIH})$ and may appear even after a single exposure to an opioid, as demonstrated in both animals and humans $(4,10)$. Among the potential mechanisms leading to $\mathrm{OIH}$, excitatory amino acids play a major role in pain sensitization, primarily through the activation of $\mathrm{N}$-methyl-D-aspartate (NMDA) receptors $(4,11-14)$. Persistent excitatory neuroplasticity is now considered to be a major potential mechanism for the development of chronic pain and changes in opioid sensitivity, leading to tolerance to analgesic effects of opioids $(2,5,15)$. However, whether $\mathrm{OIH}$ represents a 'universal phenomenon' remains a matter of debate. A substantial and growing amount of literature in clinical and basic research supports the idea

\author{
Les différences d'hypersensibilité à la douleur \\ exogène et endogène induite par les opioïdes dans \\ des souches murines
}

HISTORIQUE : L'hyperalgésie induite par les opiö̈des (HIO) est une complication connue de l'utilisation des opioïdes qui peut favoriser l'apparition d'une douleur exagérée après une opération.

OBJECTIF : Examiner le rôle des facteurs génétiques de l'HIO en comparant quatre souches murines. Puisque les auteurs ont déjà rendu compte que les opioïdes endogènes libérés pendant un stress environnemental non nociceptif induisent également une sensibilisation latente à la douleur, ils ont également évalué les interactions entre les facteurs génétiques et environnementaux.

MÉTHODOLOGIE : D'abord, les chercheurs ont comparé la propension des rats Sprague Dawley, Wistar, Lewis et Fischer à présenter une HIO après une exposition unique ou répétée au fentanyl en mesurant leur seuil nociceptif au moyen du test de vocalisation induite par pression de la patte. Ensuite, ils ont exposé des rats Sprague Dawley et Fischer à une série de trois séances de stress environnemental non nociceptif pour évaluer la capacité des opioïdes endogènes à accroître l'hyperalgie associée à une inflammation de la patte arrière induite par le carraghénane deux semaines plus tard.

RÉSULTATS : Les rats Sprague Dawley, Wistar et Lewis ont présenté une $\mathrm{HIO}$, mais des différences s'observaient entre chaque souche. L'hyperalgie inflammatoire induite par un stress antérieur augmentait chez les rats Sprague Dawley, mais pas chez les rats Fischer.

CONCLUSIONS : Le niveau de douleur reflète non seulement les afférences nociceptives, mais dépend également à la fois des antécédents et des facteurs génétiques de l'individu. Les modèles génétiques et environnementaux peuvent donner de nouveaux aperçus des mécanismes qui sous-tendent les différences observées en matière de douleur postopératoire.

that genetic factors influence pain sensitivity and the analgesic potency of exogenous opioids (16-20).

In comparison, the ability of endogenous opioids to also activate pronociceptive pathways has been poorly studied using genetics. Although stress associated with endogenous opioid release induces analgesia, there is a compelling body of evidence in humans to suggest that unmanaged negative emotions associated with stressful events can lead to exaggerated pain such as postoperative pain (21). In preclinical experiments, we recently demonstrated in rats that opioid-dependent stress primarily induces analgesia and secondarily induces long-lasting and latent pain hypersensitivity through an NMDA-dependent process, which results in an exaggerated pain in response to further noxious stimulation (22).

Based on these data, the purpose of the present study was to compare changes in pain sensitivity induced through exogenous or endogenous opioids in several rat strains. First, we compared the ability of a single or repeated fentanyl exposure to induce $\mathrm{OIH}$ in four rat strains (Sprague Dawley, Wistar, Lewis and Fischer). Second, we used an experimental model of latent pain sensitization (22) induced using

Team Homéostasie-Allostasie-Pathologie-Réhabilitation, UMR CNRS 5287 Université Bordeaux Segalen, Bordeaux; ${ }^{2}$ Department of

Anesthesiology and Critical Care, Université Claude Bernard Lyon 1, Groupe Hospitalier Nord, hôpital de la Croix Rousse, Lyon;

${ }^{3}$ Department of Anesthesiology and Critical Care, CHU Pitié Salpétrière, Paris, France

Correspondence: Dr Guy Simonnet, Team Homéostasie-Allostasie-Pathologie-Réhabilitation, UMR CNRS 5287 INCIA, Université Bordeaux

Segalen, 146 Rue Léo Saignat, F-33076 Bordeaux, France. Telephone 33-557571406, fax 33-557571412, e-mail gsimonnet@yahoo.com 
a series of opioid-dependent, non-nociceptive environmental stressors to evaluate the ability of endogenous opioids to render Sprague Dawley and Fischer rats more sensitive to further nociceptive inputs associated with inflammation in the hind paw.

\section{METHODS}

\section{Animals}

The experiments were performed using adult male Sprague Dawley ( $300 \mathrm{~g}$ to $350 \mathrm{~g}$ ), Fischer 344 ( $200 \mathrm{~g}$ to $250 \mathrm{~g}$ ), Lewis ( $250 \mathrm{~g}$ to $300 \mathrm{~g}$ ) or Wistar (250 g to $300 \mathrm{~g}$ ) rats (Charles River Laboratories, l'Arbresle, France). All rats were six weeks of age on arrival at the laboratory and were used in experiments at eight to 11 weeks of age. The rats were housed in groups of four or five per cage with a $12 \mathrm{~h}$ light/dark cycle (lights on at 07:00) at a constant temperature of $23 \pm 2^{\circ} \mathrm{C}$. Food and water were provided ad libitum. All experiments were performed during the light period. The present study was approved by the Institutional Review Board for animal research (Comité d'Ethique pour l'Expérimentation Animale Bordeaux, CEEA50 in Comité National de Réflexion Ethique sur l'Expérimentation Animale, France), and all experiments were conducted in a manner that does not inflict unnecessary pain or discomfort on the animals, in according with the United States Public Health Service Policy on the Humane Care and Use of the Laboratory Animals and the Guide for the Care and Use of Laboratory Animals (2011), prepared by the National Academy of Sciences Institute for Laboratory Animal Research. These experiments were conducted in an authorized laboratory under the supervision of a certified researcher, Emilie Laboureyras (certification no. B33 12 017, delivered by the Direction Départementale des Services Vétérinaires de la Gironde, France).

\section{Drugs}

Fentanyl citrate, naloxone and carrageenan $\lambda$ (Sigma-Aldrich, France) were dissolved in physiological saline $(0.9 \%)$. Fentanyl $(60 \mu \mathrm{g} / \mathrm{kg}$ or $100 \mu \mathrm{g} / \mathrm{kg})$ and naloxone $(1 \mathrm{mg} / \mathrm{kg})$ were administered subcutaneously ( $1 \mathrm{~mL} / \mathrm{kg}$ body weight). The control animals received an equal volume of saline injections. Carrageenan $\lambda(0.2 \mathrm{~mL}$ of a $1 \%$ solution $)$ was prepared $24 \mathrm{~h}$ before each experiment and subcutaneously injected into one rat plantar hind paw.

\section{Measurement of the nociceptive threshold}

The nociceptive thresholds (NT) in the handled rats were determined using the modified Randall-Selitto method as previously described (3). Briefly, a paw pressure vocalization test was performed, in which constant increasing pressure was applied to the hind paw until the rat squeaked. A Basile analgesimeter (Bioseb, Chaville, France; stylus tip diameter $1 \mathrm{~mm}$ ) was used with a $600 \mathrm{~g}$ cut-off value to prevent tissue damage. In all experiments, the nociceptive thresholds were evaluated in both hind paws.

\section{Opioid treatment model}

To mimic the high-dose opioid treatment used in human surgeries, fentanyl ( $60 \mu \mathrm{g} / \mathrm{kg}$ or $100 \mu \mathrm{g} / \mathrm{kg}$ subcutaneous) was injected four consecutive times every $15 \mathrm{~min}$, resulting in a total fentanyl dose of $240 \mu \mathrm{g} / \mathrm{kg}$ or $400 \mu \mathrm{g} / \mathrm{kg}$.

\section{Non-nociceptive environmental stress}

Non-nociceptive environmental stress (NNES) involved exposure to a novel environment for $1 \mathrm{~h}$, as previously described (23). The rats were placed in a new experimental room in new cages with fresh bedding, and the animals were then exposed to a light (350 lux) placed $2 \mathrm{~m}$ away from the cages. At the end of the stress session, the rats were returned to their home cages in the original experimental room. The nonstressed animals were maintained in their home cages.

\section{Fentanyl ultra-low dose test}

As previously reported (23), a subcutaneous fentanyl dose was used to induce analgesia similar to the NNES-induced analgesia observed in the naive rats. In contrast, the administration of an ultra-low dose of fentanyl (fULD) $(50 \mathrm{ng} / \mathrm{kg}$ ) to pain- or opioid-experienced rats induced paradoxical hyperalgesia, which differed from the analgesia observed in rats without previous pain or opioid experiences. This finding suggested that behavioural responses to a fULD administration could be used as a pharmacological method to detect pain vulnerability (latent pain hypersensitivity) and predict exaggerated pain responses to further noxious stimuli.

\section{Inflammatory pain model}

The rats were placed in a plastic cage and were subsequently anesthetized using $3 \%$ isoflurane for $3 \mathrm{~min}$. Carrageenan $\lambda(0.2 \mathrm{~mL}$ of a $1 \%$ carrageenan solution in saline) was then subcutaneously injected into the left hind paw using a 25-gauge needle.

\section{Experimental procedure}

Following arrival at the laboratory, the animals were randomly assigned to different experimental groups and were acclimatized to the animal care unit for four days. To avoid experimental perturbations that may affect the NT measurement, the same experimenter performed these experiments under quiet conditions in a test room near the animal care unit. For eight days before the start of the experiments, the animals were placed in the test room for $2 \mathrm{~h}$ daily to acclimate. In this test room, the animals were weighed daily and gently handled for $5 \mathrm{~min}$. All experiments were performed on groups of 10 animals during the light cycle. NT assessments were performed on the day (ie, on $\left.D_{-1}\right)$ preceding the experimental day $\left(D_{0}\right)$ and were repeated on the experimental day immediately before opioid administration $\left(D_{0}\right)$. The experiments were only initiated when there were no statistical changes in the basal NT for two successive days $\left(D_{-1}\right.$ and $D_{0}$; one-way ANOVA; $\mathrm{P}>0.05)$. The animals were tested at the same time each day. The reference value of the NT was selected as the basal value on $\mathrm{D}_{0}$. In addition, the experimenter was blinded to the treatment conditions.

Experiment 1: Effects of a single fentanyl administration on the nociceptive threshold in four rat strains: Four groups of 10 rats each were formed using the following rat strains: Sprague Dawley, Wistar, Lewis and Fischer. Each rat received a subcutaneous administration of fentanyl $(4 \times 60 \mu \mathrm{g} / \mathrm{kg})$ on $\mathrm{D}_{0}$. The NT was evaluated every $30 \mathrm{~min}$ after fentanyl administration on $\mathrm{D}_{0}$ until the return to baseline and once daily on subsequent days until the return to the basal level. At the end of the experiment, the rats received a subcutaneous injection of naloxone $(1 \mathrm{mg} / \mathrm{kg})$ and the NT was measured at $5 \mathrm{~min}$ after the injection.

Experiment 2: Comparative effects of repeated fentanyl administrations on the nociceptive threshold in Sprague Dawley and Fischer rats: Two groups of 10 rats each were formed using Sprague Dawley and Fischer rats. Each rat received a subcutaneous injection of fentanyl $(4 \times 100 \mu \mathrm{g} / \mathrm{kg})$ on $\mathrm{D}_{0}, \mathrm{D}_{6}$ and $\mathrm{D}_{15}$ when the NT had returned to baseline. The NT was evaluated every $30 \mathrm{~min}$ after fentanyl administration on the experimental day until the return to baseline and once daily on subsequent days. At the end of the experiment $\left(D_{32}\right)$, the rats received a subcutaneous injection of naloxone $(1 \mathrm{mg} / \mathrm{kg})$ and the NT was measured $5 \mathrm{~min}$ after the injection.

Experiment 3: Comparative effects of pre-exposures to NNES on changes in the nociceptive threshold induced by fULD and subsequent inflammation in Sprague Dawley and Fischer rats: Four groups of 10 rats each were formed using nonstressed Sprague Dawley rats, stressed Sprague Dawley rats, nonstressed Fischer rats and stressed Fischer rats. On $D_{0}$ and $D_{9}$, the rats received a fULD (50 ng/kg) injection to determine whether the stress sessions on $\mathrm{D}_{1}, \mathrm{D}_{3}$ and $\mathrm{D}_{8}$ could change the response to fULD. The NT was assessed every $30 \mathrm{~min}$ after fentanyl injection for $4.5 \mathrm{~h}$. The NNES was performed on $\mathrm{D}_{1}, \mathrm{D}_{3}$ and $\mathrm{D}_{8}$ for $1 \mathrm{~h}$. The NT was measured for $30 \mathrm{~min}, 1.5 \mathrm{~h}, 2.5 \mathrm{~h}$ and $4.5 \mathrm{~h}$ after the initiation of stress. On $\mathrm{D}_{11}$, a carrageenan injection was performed in the left hind paw. NT was evaluated at $2 \mathrm{~h}, 4 \mathrm{~h}$ and $6 \mathrm{~h}$ after the carrageenan injection and once daily on subsequent days until the return to baseline. 
Statistical analysis

Data are presented as mean \pm SEM. Repeated-measures two-way ANOVAs according to the factors of time (within) and group (between) were performed using Statistica 5.1 software (Statsoft, Maisons-Alfort, France). When the ANOVAs demonstrated a significant time effect $(\mathrm{P}<0.05)$, the Newman Keuls post hoc test was used to assess the differences between each time point and the baseline value on $\mathrm{D}_{0}$. When the ANOVAs demonstrated a significant group effect and/or a time-group interaction $(\mathrm{P}<0.05)$, the Newman Keuls post hoc test was used to assess the differences between groups. Analgesic or hyperalgesic indexes, represented by the area under or above the curve, respectively, were calculated for each rat using the trapezoidal method. As previously reported (3), surface areas were calculated by summing the NT values measured daily after the planned experimental day according the formula: Surface $=\Sigma\left(\right.$ nociceptive threshold at $\left.D_{n+1}\right)-$ basal value
\[ \times(n+1) \]

The $\mathrm{n}$ value indicates the number of days with an NT significantly different (one-way ANOVA and Newman Keuls test, $\mathrm{P}<0.05$ ) from the nociceptive threshold basal value. A one-way ANOVA was used to compare the analgesic or hyperalgesic indices following fULD administration or carrageenan injection. When the ANOVA revealed a significant group effect, the Newman Keuls post hoc test was used to determine the differences between groups. The differences were considered to be statistically significant at $\mathrm{P}<0.05$.

\section{RESULTS}

Experiment 1: Effects of a single fentanyl administration on the nociceptive threshold in four rat strains

The administration of fentanyl $(4 \times 60 \mu \mathrm{g} / \mathrm{kg})$ induced an immediate NT increase (Figure 1) that lasted for $3 \mathrm{~h}$ (Newman Keuls test, $\mathrm{P}<0.05$ ) in Lewis and Wistar rats and $3.5 \mathrm{~h}$ (Newman Keuls test, $\mathrm{P}<0.05)$ in Sprague Dawley and Fischer rats. This increase was followed by a significant early NT decrease in Sprague Dawley and Lewis rats, but no NT decrease was observed in Wistar or Fischer rats (oneway ANOVA, P>0.05; no time effect). In addition, a significant longlasting NT decrease was observed several days after fentanyl administration in Sprague Dawley (duration three days, Newman Keuls test, $\mathrm{P}<0.05$ ), Lewis (duration seven days, Newman Keuls test, $\mathrm{P}<0.05$ ) and Wistar (duration six days, Newman Keuls test, $\mathrm{P}<0.05$ ) rats, although no NT decrease following fentanyl administration was observed in Fischer rats (one-way ANOVA, P>0.05, no time effect). Naloxone administration at the end of the experiment induced an NT decrease in Sprague Dawley, Lewis and Wistar rats (Newman Keuls test, $\mathrm{P}<0.05$ ) but not in Fischer rats (one-way ANOVA, $\mathrm{P}>0.05$, no time effect).

Experiment 2: Comparative effects of repeated fentanyl administrations on the nociceptive threshold in Sprague Dawley and Fischer rats

In Sprague Dawley rats, the first administration of a higher dose of fentanyl $(4 \times 100 \mu \mathrm{g} / \mathrm{kg})$ induced an NT increase followed by an early NT decrease (Newman Keuls test, $\mathrm{P}<0.05)$. A delayed and sustained NT decrease was also observed for three days after the first fentanyl administration (Newman Keuls test, $\mathrm{P}<0.05$ ) (Figure $2 \mathrm{~A}$ ). The second administration of fentanyl $(4 \times 100 \mu \mathrm{g} / \mathrm{kg})$ on $\mathrm{D}_{6}$ elicited an NT increase followed by an equivalent early NT decrease (Newman Keuls test, $\mathrm{P}<0.05)$. Moreover, a longer delayed NT decrease was observed for eight days following the second fentanyl administration (Newman Keuls test, $\mathrm{P}<0.05)$ (Figure 2A). Interestingly, the third administration of fentanyl $(4 \times 100 \mu \mathrm{g} / \mathrm{kg})$ on $\mathrm{D}_{15}$ elicited an NT increase followed by a very important delayed NT decrease (Newman Keuls test, $\mathrm{P}<0.05$ ). In addition, a longer delayed NT decrease was observed for 13 days following the third fentanyl administration (Newman Keuls test, $\mathrm{P}<0.05)$. According to the AUC calculations, the second and third fentanyl administrations induced 1.2- and 1.7-fold increases in the

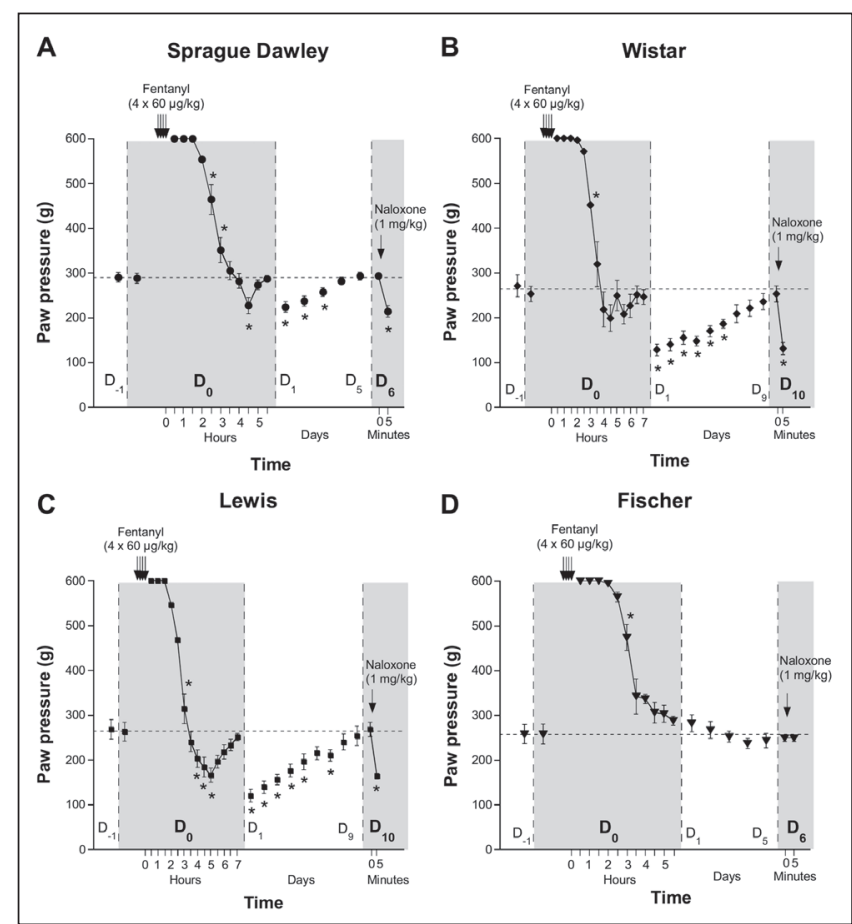

Figure 1) Effects of a single fentanyl administration on the nociceptive threshold (NT) in four rat strains. Changes in the NT were evaluated using a paw pressure vocalization test at the hind paw in Sprague Dawley (A), Wistar (B), Lewis (C) and Fischer (D) rats. Fentanyl administration was performed on day $0\left(D_{0}\right)$. Fentanyl (60 $\mu g / k g$ subcutaneous) was injected four consecutive times every $15 \mathrm{~min}$, resulting in a total fentanyl dose of $240 \mu \mathrm{g} / \mathrm{kg}$. NT was assessed on $D_{-1}$ and $D_{0}$ every $30 \mathrm{~min}$ after the first fentanyl injection until the return to the basal values on $D_{0}$ and subsequently once daily. Once the NT had returned to baseline, naloxone was injected (1 mg/kg subcutaneous) and the NT was assessed 5 min later. The mean $( \pm$ SEM) pressure values that triggered vocalization are expressed in $g$ ( $n=10$ for each group). *Newman Keuls test, $P<0.05$ for comparisons with the basal value

early NT decrease, respectively, compared with the first fentanyl administration. Similarly, the second and third fentanyl administration induced three- and 5.8-fold increases in the delayed NT decrease, respectively.

In Fischer rats, three administrations of fentanyl $(4 \times 100 \mu g / \mathrm{kg})$ elicited NT increases (Newman Keuls test, $\mathrm{P}<0.05$ ) (Figure 2B). However, neither early nor delayed NT decreases were observed in Fischer rats following three fentanyl administrations (one-way ANOVA, P>0.05; no time effect).

Experiment 3: Comparative effects of pre-exposure to NNES on changes in the nociceptive threshold induced by fULD and subsequent inflammation in Sprague Dawley and Fischer rats The fULD administration on $D_{0}$ induced a similar NT increase for $30 \mathrm{~min}$ in both Sprague Dawley and Fischer rats (one-way ANOVA, $\mathrm{P}>0.05$; no group effect). In Sprague Dawley rats (Figures 3A and 4A), the first NNES on $D_{1}$ induced analgesia limited to the time of the stress exposure (Newman Keuls test, $\mathrm{P}<0.05)$. The amplitude of the stress-induced analgesia decreased with stressor repetition (Newman Keuls test, $\mathrm{P}<0.05)$. No change in the baseline NT was observed in nonstressed rats (one-way ANOVA, $\mathrm{P}>0.05$ ). In nonstressed rats, the fULD administration on $D_{9}$ induced a NT increase for $30 \mathrm{~min}$ (Newman Keuls test, $\mathrm{P}<0.05)$. In contrast, the fULD administration resulted in a decrease in the NT that lasted for $4 \mathrm{~h}$ (Newman Keuls test, $\mathrm{P}<0.05)$ in stressed rats. In nonstressed rats, an intraplantar carrageenan injection on $\mathrm{D}_{11}$ induced a decrease in the NT in the 


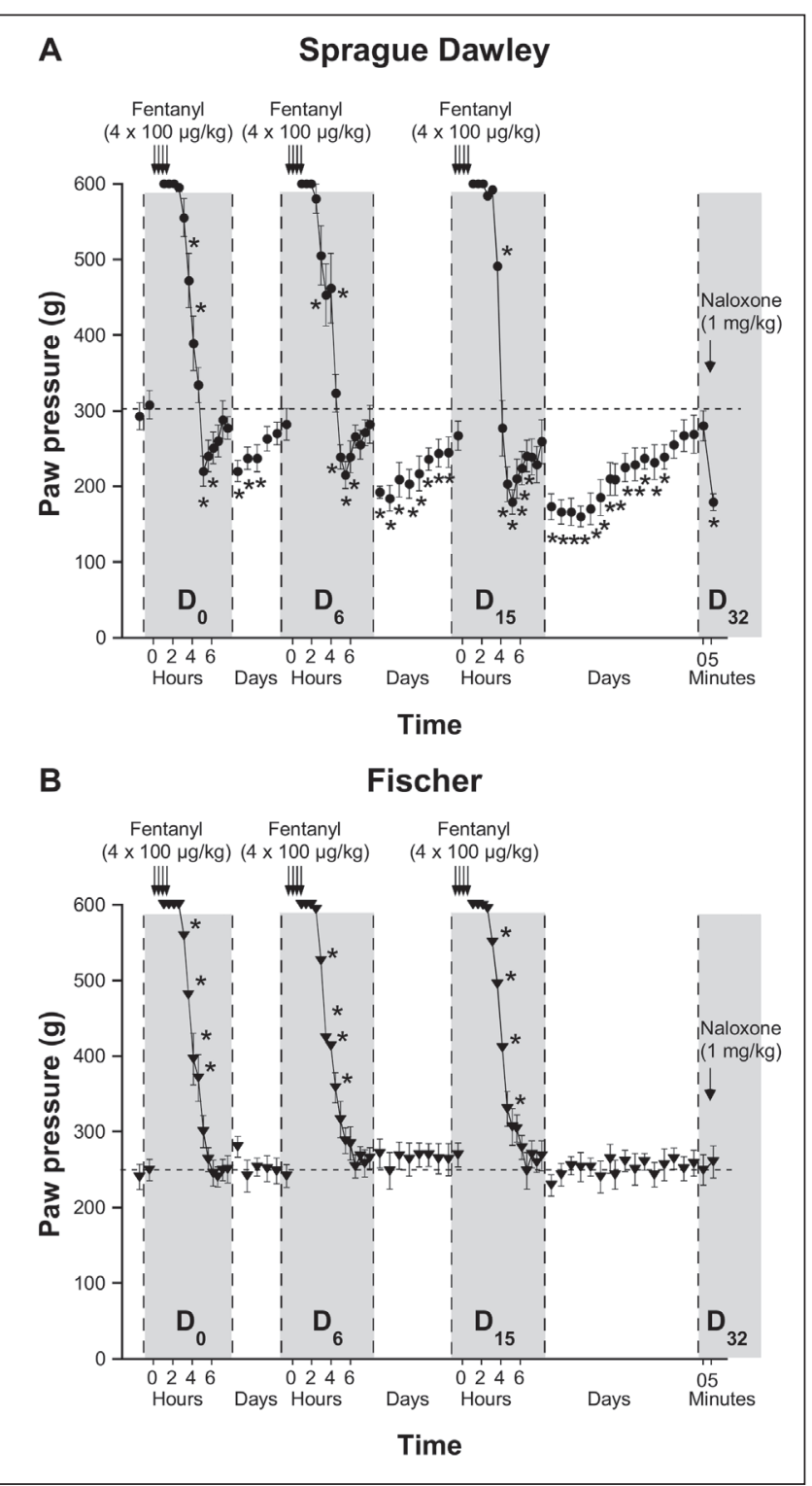

Figure 2) Comparative effects of repeated fentanyl administrations on the nociceptive threshold (NT) in Sprague Dawley and Fischer rats. Changes in the NT were evaluated using a paw pressure vocalization test at the hind paw in Sprague Dawley (A) and Fischer (B) rats. The first fentanyl administration was performed on day $0\left(D_{0}\right)$. Fentanyl $(100 \mu g / k g ~ s u b-$ cutaneous) was injected four consecutive times every $15 \mathrm{~min}$, resulting in a total fentanyl dose of $400 \mu \mathrm{g} / \mathrm{kg}$. Fentanyl administration $(4 \times 100 \mu \mathrm{g} / \mathrm{kg})$ was repeated on $D_{6}$ and $D_{15}$. NT was assessed on $D_{-1}$ and $D_{0}$ every 30 min after the fentanyl injection until the return to basal values on $D_{0}$ and subsequently once daily. Once the NT had returned to baseline after the third fentanyl administration, naloxone was injected ( $1 \mathrm{mg} / \mathrm{kg}$ subcutaneous) and the NT was evaluated 5 min later. The mean ( \pm SEM) pressure values that triggered vocalization are expressed in $g(n=10$ for each group). *Newman Keuls test, $P<0.05$ for comparisons with the basal value

inflamed hind paw that lasted for four days (Figure 3A; Newman Keuls test, $\mathrm{P}<0.05)$ and a limited NT decrease in the contralateral noninflamed hind paw that lasted for several hours. No NT decrease was observed in the noninflamed hind paw on the days following the carrageenan injection (Figure 4A; one-way ANOVA, P>0.05, no time effect). In stressed rats, an intraplantar carrageenan injection on $\mathrm{D}_{11}$ induced a decrease in the NT of the inflamed and noninflamed hind

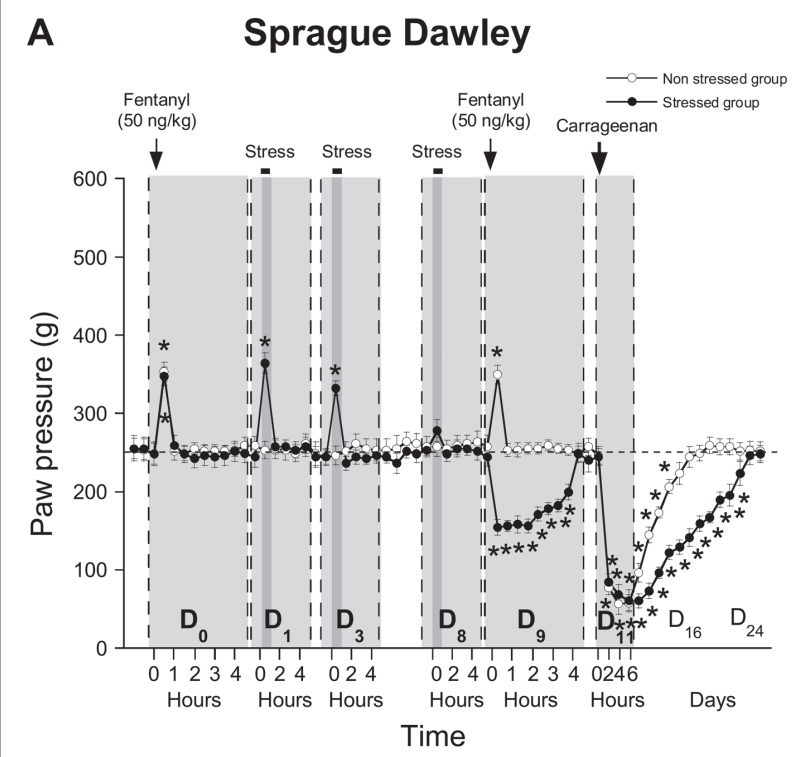

B

Fischer

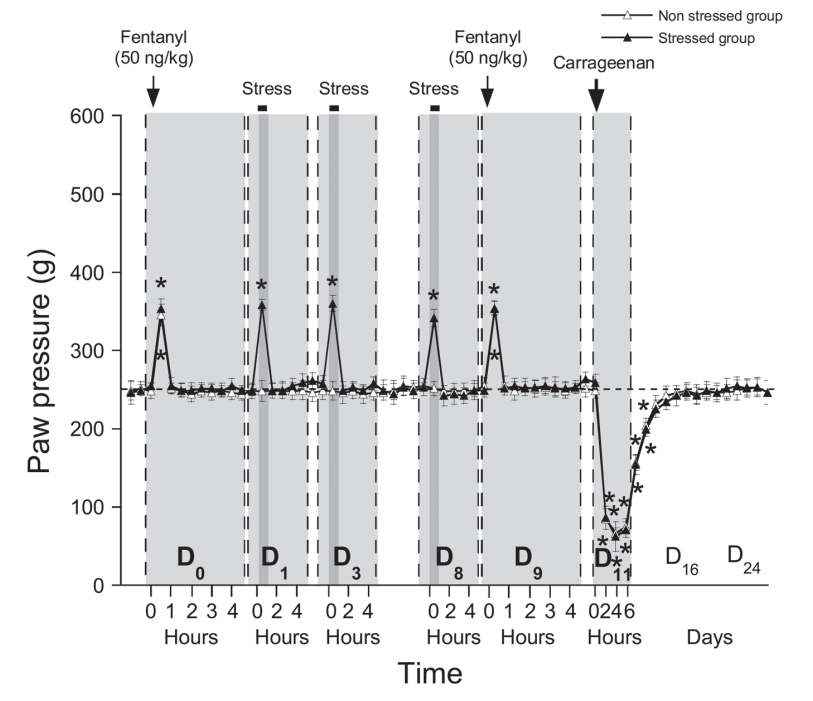

Figure 3) Comparative effects of pre-exposures to non-nociceptive environmental stress on changes in the nociceptive threshold induced by fentanyl ultra-low dose (fULD) and subsequent inflammation at the ipsilateral hind paw level in Sprague Dawley and Fischer rats. Changes in the nociceptive threshold were evaluated using a paw pressure vocalization test on the inflamed hind paws of Sprague Dawley (A) and Fischer (B) rats. On day $O\left(D_{0}\right)$, all rats received $f U L D$ administration $(50 \mathrm{ng} / \mathrm{kg}$ subcutaneous). The non-nociceptive environmental stress was performed on $D_{1}, D_{3}$ and $D_{8}$ for animals in the stressed groups. On $D_{9}$, a second fULD administration (50 $\mathrm{ng} / \mathrm{kg}$ subcutaneous) was performed on all rats. On $D_{11}$, the animals received an intraplantar carrageenan $\lambda$ injection $(0.2 \mathrm{~mL}, 1 \%)$. The mean ( \pm SEM) pressure values that triggered vocalization are expressed in $g$ ( $n=8$ for each group). *Newman Keuls test, $P<0.05$ for comparisons with the basal value

paws that lasted for 11 days (Figure 3A; Newman Keuls test, $\mathrm{P}<0.05$ ) and nine days (Figure 4A; Newman Keuls test, $\mathrm{P}<0.05$ ), respectively. Moreover, the hyperalgesic indices were increased by threefold in the inflamed hind paw compared with nonstressed group (data not shown, Newman Keuls test, $\mathrm{P}<0.05)$.

In Fischer rats (Figures $3 \mathrm{~B}$ and $4 \mathrm{~B}$ ), the first NNES on $\mathrm{D}_{1}$ induced analgesia limited to the time of the stress exposure (Newman Keuls 
test, $\mathrm{P}<0.05)$. In contrast to stressed Sprague Dawley rats, no change in the amplitude of the stress-induced analgesia was observed with stressor repetition (one-way ANOVA, P>0.05; no time effect). No change in the baseline NT was observed in nonstressed rats (one-way ANOVA, $P>0.05$ ). The fULD administration on $\mathrm{D}_{9}$ induced a similar NT increase that lasted for $30 \mathrm{~min}($ Newman Keuls test, $\mathrm{P}<0.05)$ in both nonstressed and stressed rats. In nonstressed rats, an intraplantar carrageenan injection on $D_{11}$ induced an NT decrease in the inflamed hind paw that lasted for two days (Figure 3B; Newman Keuls test, $\mathrm{P}<0.05)$. No NT decrease was observed in the contralateral noninflamed hind paw on the days following the carrageenan injection (Figure 4B; one-way ANOVA, P>0.05, no time effect). In stressed rats, an intraplantar carrageenan injection on $\mathrm{D}_{11}$ induced a NT decrease in the inflamed hind paw that lasted for two days (Figure 3B; Newman Keuls test, $\mathrm{P}<0.05$ ), but no NT decrease was observed in the contralateral noninflamed hind paw on the days following the carrageenan injection (Figure 4B; one-way ANOVA, P>0.05; no time effect). No increases in the hyperalgesic indices were observed for the inflamed hind paw of stressed animals compared with nonstressed animals (oneway ANOVA, $\mathrm{P}>0.05)$. The amplitude of hyperalgesia in the nonstressed and stressed Fischer rats was lower $(-60 \%)$ than that observed in nonstressed Sprague Dawley rats (Figures 3A and 3B).

\section{DISCUSSION}

The results of the present study revealed considerable interstrain differences in the ability of acute or repeated fentanyl administrations to induce $\mathrm{OIH}$ in rats. $\mathrm{OIH}$ was not observed in Fischer rats even after three fentanyl injections. Similarly, the enhancement in pain sensitivity, ie, latent pain sensitization, induced by previous endogenous opioid release associated with NNES in Sprague Dawley rats was not observed in Fischer rats.

Although some differences in the $\mathrm{OIH}$ were observed in both the amplitude and duration of the OIH, Sprague Dawley, Wistar and Lewis strains evoked a similar biphasic pattern, ie, analgesia followed by a sustained hyperalgesia. These changes were observed using a pain vocalization mechanical test. OIH to noxious and mechanical stimuli have also been reported using the measurement of withdrawal latencies in rats (11) and mice (19) treated with various opioids such as morphine, fentanyl, remifentanil and alfentanil. In contrast, Fischer rats showed fentanyl-induced analgesia, but $\mathrm{OIH}$ was not observed in this rat strain after the first series of $4 \times 100 \mu \mathrm{g} / \mathrm{kg}$ fentanyl injections. To determine whether Fischer rats were less sensitive to fentanyl for inducing OIH compared with Sprague Dawley rats, we repeated fentanyl administrations using the highest fentanyl dose. In Sprague Dawley rats, the repetition of fentanyl injections markedly enhanced both early and delayed hyperalgesia but, in contrast, OIH was never observed in Fischer rats. Consistent with these results, naloxone injection precipitated hyperalgesia in Sprague Dawley, Wistar and Lewis rats when the opioid receptor antagonist was administered to animals that had attained the predrug nociceptive threshold value. In contrast, naloxone did not precipitate hyperalgesia in fentanyl-treated Fischer rats. Because naloxone induces an effect in rats that recover from $\mathrm{OIH}$, it has been previously suggested (24-26) that the injection of an opioid antagonist may unmask a new biological equilibrium (allostasis) associated with a high-level balance between endogenous opioid-dependent analgesic systems and counteracting systems (ie, NMDA-dependent pronociceptive systems $[11,12]$ ), which can mask one another for a long period of time $(2,5)$. The activation of opposing pronociceptive processes, potentially promoting a changed set point $(5,26-29)$, would not be activated in Fischer rats. Collectively, this first series of experiments clearly shows major differences between Fischer rats on the one hand, and Sprague Dawley, Wistar and Lewis rats on the other, in the development and the expression of $\mathrm{OIH}$. These results suggest that a potent synthetic opioid, such as fentanyl, cannot trigger the activation of NMDA-dependent pronociceptive systems in the Fischer rat strain.

These results led us to evaluate whether endogenous opioids induce pain hypersensitivity using a recently developed NNES

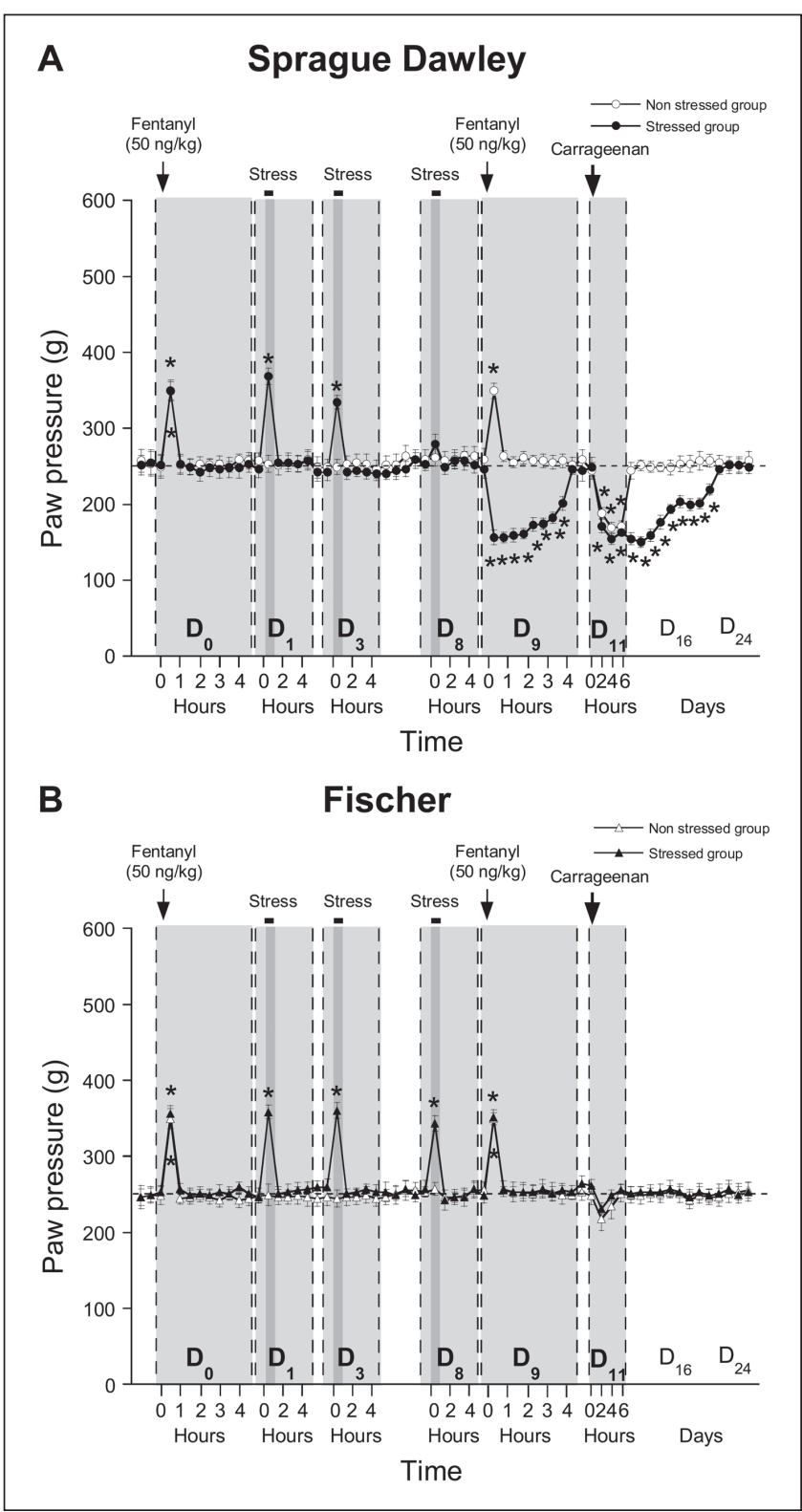

Figure 4) Comparative effects of pre-exposures to non-nociceptive environmental stress on changes in the nociceptive threshold induced by fentanyl ultra-low dose (fULD) and subsequent inflammation at the contralateral hind paw level in Sprague Dawley and Fischer rats. Changes in the nociceptive threshold were evaluated using a paw pressure vocalization test on the noninflamed hind paws of Sprague Dawley (A) and Fischer (B) rats. On day $O\left(D_{0}\right)$, all rats received $f U L D$ administration $(50 \mathrm{ng} / \mathrm{kg}$ subcutaneous). The non-nociceptive environmental stress was performed on $D_{1}, D_{3}$ and $D_{8}$ for animals in the stressed groups. On $D_{9}$, a second fULD administration (50 ng/kg subcutaneous) was performed in all rats. On $D_{11}$, the animals received an intraplantar carrageenan injection $(0.2 \mathrm{~mL}, 1 \%)$. The mean $( \pm$ SEM) pressure values that triggered vocalization are expressed in $g$ ( $n=8$ for each group). *Newman Keuls test, $P<0.05$ for comparisons with the basal value

paradigm. In a previous Sprague Dawley rat study (22), we showed that endogenous opioids, released during NNES, could induce immediate analgesia and secondarily induce an NMDA-dependent latent pain sensitization, leading to exaggerated pain in response to further noxious stimulation two weeks later. Interestingly, the blockade of opioid receptors by naltrexone before each stress session inhibited 
stress-induced analgesia and suppressed the enhanced inflammatory hyperalgesia observed in prestressed Sprague Dawley rats. This result suggests that endogenous opioids paradoxically play a major role in the development of latent pain sensitization. Using this original protocol in Fischer rats, several differences were observed with Sprague Dawley rats. First, inflammatory hyperalgesia was more moderate in Fischer rats compared with Sprague Dawley rats. Second, previous NNES in Fischer rats did not enhance inflammatory hyperalgesia in the inflamed hind paw, as observed in the Sprague Dawley rats. Third, in contrast to results obtained in Sprague Dawley rats, prestressed and nonstressed Fischer rats did not show pain hypersensitivity in the contralateral noninflamed hind paw. Consistent with our previous data (22), the present study confirms that prestressed and nonstressed Sprague Dawley rats can be experimentally distinguished according to their hyperalgesic or analgesic responses to fULD, respectively. In contrast, prestressed Fischer rats always evoked fULD analgesia and not fULD hyperalgesia. This result confirms that fULD analgesic/ hyperalgesic indexes facilitate experimental predictions of individual pain vulnerability in various rat strains. As observed in $\mathrm{OIH}$ with exogenous opioids, Fischer rats are less sensitive to the development of pain sensitization following opioid receptor activation through endogenous opioids. Interestingly, we previous demonstrated in Sprague Dawley rats that latent pain hypersensitivity induced through endogenous opioid release associated with previous NNES are prevented using NMDA receptor antagonists (22). Consistent with a potential difference in NMDA receptor functioning in Fischer rats versus other rat strains, prenatal stress increases the hippocampal expression of Grin2b (one of four NR2 subunit types containing NMDA receptors) in Sprague Dawley and Lewis rats but not in the Fischer rat strain, although similar baseline levels were observed (30). Thus, these results indicate that environmental influences on individual pain sensitivity are dependent on genetic factors.

Although several mechanisms, including various neural and glial components at the spinal and supraspinal levels (19,31-42), have been suggested to mediate the development of $\mathrm{OIH}$, the activation of the NMDA receptor complex by $\mu$ receptor agonists is one of the most important underlying mechanisms for the development of abnormal pain hypersensitivity induced by both exogenous $(2,5,6,15,22,43)$ and endogenous opioids (22). However, genetic analyses suggest that the $\beta 2$-adrenergic receptor (44), the 5-HT3 receptor (45) and the P-glycoprotein gene Abcblb (46) contribute to the differences observed among various strains of mice that develop OIH. From a clinical point of view, the experimental models developed in the present study may be effective tools to provide a better understanding of the mechanisms that underlie individual differences observed in pain sensitivity in humans, particularly after surgical injuries.

Collectively, our results suggest that $\mathrm{OIH}$, fULD hyperalgesia and latent pain sensitization have common mechanisms because these conditions are triggered through the activation of opioid receptors and prevented by the administration of NMDA receptor antagonists $(3,22,23)$. Although medically unpleasant, hyperalgesia induced by exogenous opioid administration and latent pain sensitization induced by previous endogenous opioid release (in the context of individual stress histories) should be considered as adaptive responses because these mechanisms provide reinforcement for a coordinated set of behavioural drives based on memories of dangerous events following exposure to threats. Indeed, it has been speculated that pain hypersensitivity facilitates learning processes to avoid environmental changes leading to tissue injuries and associated pain. Interestingly, pain hypersensitivity has also been described following analgesia induced through triptan overuse (47) or $\alpha 2$-adrenergic agonist administration (48). Consistent with the compensatory response hypothesis $(5,29,49)$, particularly with regard to the opponent process theory (27), it can be speculated that an excess of various druginduced analgesia leads to abnormal pain vulnerability. Paradoxically, Fischer rats appear to be less adapted to environmental changes compared with other rat strains because these rats demonstrated a deficit in neuroplasticity following endogenous opioid release. These preclinical results may provide support for further studies to obtain a better understanding of the role of genetic and environmental interactions in individual differences in both pain sensitivity and pharmacological responses to an opioid.

AUTHOR CONTRIBUTIONS: Emilie Laboureyras contributed to study design, conduct of the study, data collection, data analysis and manuscript preparation. Frédéric Aubrun helped to design the study and prepare the manuscript. Maud Monsaingeon contributed to study design, conduct of the study, data collection and data analysis. Jean-Benoît Corcuff helped to design the study and prepare the manuscript. Jean-Paul Laulin contributed to study design, data collection and data analysis. Guy Simonnet contributed to study design, data analysis and manuscript preparation.

DISCLOSURES: The authors have no conflicts of interest to declare. Emilie Laboureyras is the archival author. Each author approved the final manuscript and attests to the integrity of the original data and the analysis reported in this article.

FUNDING: This work was supported by the Université Bordeaux Segalen, the Université Bordeaux 1, Bordeaux, France and the CNRS, Paris, France. Dr Aubrun was the recipient of a joined research grant from Assistance Publique - Hôpitaux de Paris - CNRS and Université Bordeaux Ségalen (Postes d'accueil).

\section{REFERENCES}

1. Mao J. Opioid-induced abnormal pain sensitivity: Implications in clinical opioid therapy. Pain 2002;100:213-7.

2. Angst MS, Clark JD. Opioid-induced hyperalgesia: A qualitative systematic review. Anesthesiology 2006;104:570-87.

3. Célèrier E, Rivat C, Jun Y, et al. Long-lasting hyperalgesia induced by fentanyl in rats: Preventive effect of ketamine. Anesthesiology 2000;92:465-72.

4. Rivat C, Laulin JP, Corcuff JB, Celerier E, Pain L, Simonnet G. Fentanyl enhancement of carrageenan-induced long-lasting hyperalgesia in rats: Prevention by the $\mathrm{N}$-methyl-D-aspartate receptor antagonist ketamine. Anesthesiology 2002;96:381-91

5. Simonnet G, Rivat C. Opioid-induced hyperalgesia: Abnormal or normal pain? Neuroreport 2003;14:1-7.

6. Wilder-Smith OH, Arendt-Nielsen L. Postoperative hyperalgesia: Its clinical importance and relevance. Anesthesiology 2006;104:601-7.

7. Lee M, Silverman SM, Hansen H, Patel VB, Manchikanti L. A comprehensive review of opioid-induced hyperalgesia. Pain 2011;14:145-61.

8. Grosu I, de Kock M. New concepts in acute pain management: Strategies to prevent chronic postsurgical pain, opioid-induced hyperalgesia, and outcome measures. Anesthesiol Clin 2011;29:311-27.

9. Crofford LJ. Adverse effects of chronic opioid therapy for chronic musculoskeletal pain. Nature 2010;6:191-7.

10. Guignard B, Bossard AE, Coste C, et al. Acute opioid tolerance: Intraoperative remifentanil increases postoperative pain and morphine requirement. Anesthesiology 2000;93:409-17.

11. Mao J, Price DD, Mayer DJ. Thermal hyperalgesia in association with the development of morphine tolerance in rats: Roles of excitatory amino acid receptors and protein kinase C. J Neurosci 1994;14:2301-12.

12. Célèrier E, Laulin JP, Larcher A, Le Moal M, Simonnet G. Evidence for opiate-activated NMDA processes masking opiate analgesia in rats. Brain Res 1999;847:18-25.

13. Joly V, Richebe P, Guignard B, et al. Remifentanil-induced postoperative hyperalgesia and its prevention with small-dose ketamine. Anesthesiology 2005;103:147-55.

14. Stubhaug A, Breivik H, Eide PK, Kreunen M, Foss A. Mapping of punctuate hyperalgesia around a surgical incision demonstrates that ketamine is a powerful suppressor of central sensitization to pain following surgery. Acta Anaesthesiol Scand 1997;41:1124-32.

15. Mao J, Price DD, Mayer DJ. Mechanisms of hyperalgesia and morphine tolerance: A current view of their possible interactions. Pain 1995;62:259-74.

16. Kest B, Palmese CA, Hopkins E, Adler M, Juni A, Mogil JS. Naloxone-precipitated withdrawal jumping in 11 inbred mouse strains: 
Evidence for common genetic mechanisms in acute and chronic morphine physical dependence. Neuroscience 2002;115:463-9.

17. Kest B, Palmese CA, Juni A, Chesler EJ, Mogil JS. Mapping of a quantitative trait locus for morphine withdrawal severity. Mamm Genome 2004;15:610-7.

18. Kest B, Hopkins E, Palmese CA, Adler M, Mogil JS. Genetic variation in morphine analgesic tolerance: A survey of 11 inbred mouse strains. Pharmacol Biochem Behav 2002;73:821-8.

19. Célèrier E, Gonzalez JR, Maldonado R, Cabanero D, Puig MM. Opioid-induced hyperalgesia in a murine model of postoperative pain: Role of nitric oxide generated from the inducible nitric oxide synthase. Anesthesiology 2006;104:546-55.

20. Liang DY, Guo T, Liao G, Kingery WS, Peltz G, Clark JD. Chronic pain and genetic background interact and influence opioid analgesia, tolerance, and physical dependence. Pain 2006;121:232-40.

21. Ip HY, Abrishami A, Peng PW, Wong J, Chung F. Predictors of postoperative pain and analgesic consumption: A qualitative systematic review. Anesthesiology 2009;111:657-77.

22. Le Roy C, Laboureyras E, Gavello-Baudy S, Chateauraynaud J, Laulin JP, Simonnet G. Endogenous opioids released during non-nociceptive environmental stress induce latent pain sensitization via a NMDA-dependent process. J Pain 2011;12:1069-79.

23. Rivat C, Laboureyras E, Laulin JP, Le Roy C, Richebe P, Simonnet G. Non-nociceptive environmental stress induces hyperalgesia, not analgesia, in pain and opioid-experienced rats. Neuropsychopharmacology 2007;32:2217-28.

24. Fry JP, Herz A, Zieglgansberger W. A demonstration of naloxoneprecipitated opiate withdrawal on single neurones in the morphinetolerant/dependent rat brain. Br J Pharmacol 1980;68:585-92.

25. Basbaum AI Insights into the development of opioid tolerance [editorial]. Pain 1995;61:349-52.

26. Célèrier E, Laulin JP, Corcuff JB, Le Moal M, Simonnet G. Progressive enhancement of delayed hyperalgesia induced by repeated heroin administration: A sensitization process. J Neurosci 2001;21:4074-80.

27. Solomon RL. The opponent-process theory of acquired motivation: The costs of pleasure and the benefits of pain. Am Psychol 1980;35:691-712.

28. McEwen BS. Allostasis, allostatic load, and the aging nervous system: Role of excitatory amino acids and excitotoxicity. Neurochem Res 2000;25:1219-31.

29. Koob GF, Le Moal M. Drug addiction, dysregulation of reward, and allostasis. Neuropsychopharmacology 2001;24:97-129.

30. Neeley EW, Berger R, Koenig JI, Leonard S. Strain dependent effects of prenatal stress on gene expression in the rat hippocampus. Physiol Behav 2011;104:334-9.

31. Vanderah TW, Gardell LR, Burgess SE, et al. Dynorphin promotes abnormal pain and spinal opioid antinociceptive tolerance. J Neurosci 2000;20:7074-9.

32. King T, Gardell LR, Wang R, et al. Role of NK-1 neurotransmission in opioid-induced hyperalgesia. Pain 2005;116:276-88.

33. Koetzner L, Hua XY, Lai J, Porreca F, Yaksh T. Nonopioid actions of intrathecal dynorphin evoke spinal excitatory amino acid and prostaglandin E2 release mediated by cyclooxygenase-1 and -2 . J Neurosci 2004;24:1451-8.

34. Lenz H, Raeder J, Draegni T, Heyerdahl F, Schmelz M, Stubhaug A. Effects of COX inhibition on experimental pain and hyperalgesia during and after remifentanil infusion in humans.

Pain 2011;152:1289-97.

35. Vera-Portocarrero LP, Zhang ET, King T, et al. Spinal NK-1 receptor expressing neurons mediate opioid-induced hyperalgesia and antinociceptive tolerance via activation of descending pathways. Pain 2007;129:35-45.

36. Rivat C, Vera-Portocarrero LP, Ibrahim MM, et al. Spinal NK-1 receptor-expressing neurons and descending pathways support fentanyl-induced pain hypersensitivity in a rat model of postoperative pain. Eur J Neurosci 2009;29:727-37.

37. Zhou Y, Sun YH, Zhang ZW, Han JS. Accelerated expression of cholecystokinin gene in the brain of rats rendered tolerant to morphine. Neuroreport 1992;3:1121-3.

38. Simonin F, Schmitt M, Laulin JP, et al. RF9, a potent and selective neuropeptide FF receptor antagonist, prevents opioid-induced tolerance associated with hyperalgesia. Proc Natl Acad Sci U S A 2006;103:466-71.

39. Vardanyan A, Wang R, Vanderah TW, et al. TRPV1 receptor in expression of opioid-induced hyperalgesia. J Pain 2009;10:243-52

40. Liang DY, Li X, Clark JD. 5-hydroxytryptamine type 3 receptor modulates opioid-induced hyperalgesia and tolerance in mice. Anesthesiology 2011;114:1180-9.

41. Heinl C, Drdla-Schutting R, Xanthos DN, Sandkuhler J. Distinct mechanisms underlying pronociceptive effects of opioids. J Neurosci 2011;31:16748-56.

42. Drdla R, Gassner M, Gingl E, Sandkuhler J. Induction of synaptic longterm potentiation after opioid withdrawal. Science 2009;325:207-10.

43. Laulin JP, Larcher A, Célèrier E, Le Moal M, Simonnet G. Long-lasting increased pain sensitivity in rat following exposure to heroin for the first time. Eur J Neurosci 1998;10:782-5.

44. Liang DY, Liao G, Wang J, et al. A genetic analysis of opioidinduced hyperalgesia in mice. Anesthesiology 2006;104:1054-62.

45. Chu LF, Liang DY, Li X, et al. From mouse to man: The 5-HT3 receptor modulates physical dependence on opioid narcotics. Pharmacogenet Genomics 2009;19:193-205.

46. Liang DY, Liao G, Lighthall GK, Peltz G, Clark DJ. Genetic variants of the P-glycoprotein gene Abcblb modulate opioidinduced hyperalgesia, tolerance and dependence. Pharmacogenet Genomics 2006;16:825-35.

47. De Felice M, Ossipov MH, Wang R, et al. Triptan-induced latent sensitization: A possible basis for medication overuse headache. Ann Neurol 2009;67:325-37.

48. Quartilho A, Mata HP, Ibrahim MM, et al. Production of paradoxical sensory hypersensitivity by alpha 2-adrenoreceptor agonists. Anesthesiology 2004;100:1538-44.

49. Wise RA. The neurobiology of craving: Implications for the understanding and treatment of addiction. J Abnorm Psychol 1988;97:118-32. 


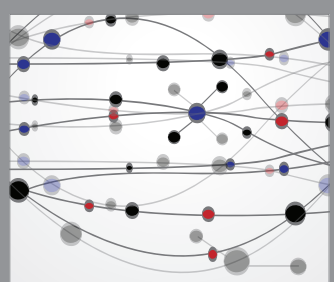

The Scientific World Journal
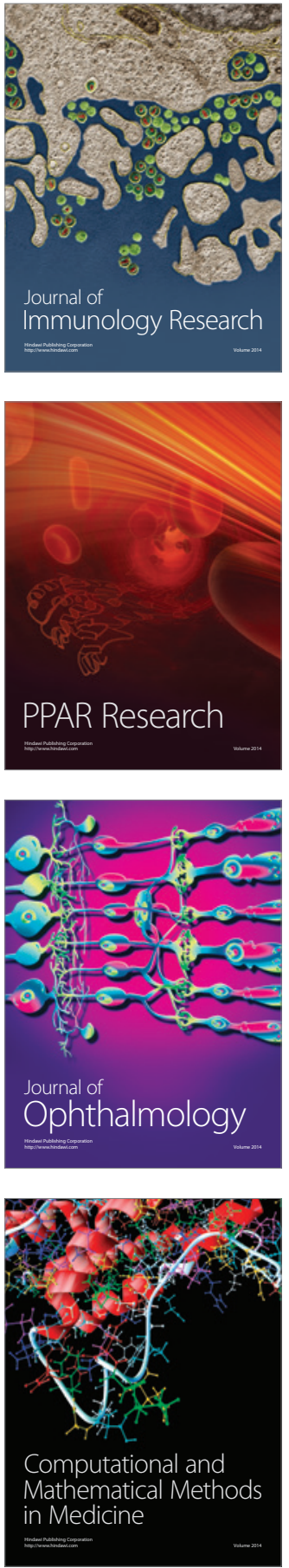

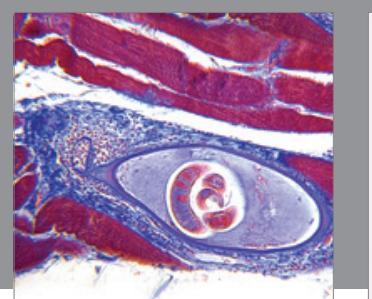

Gastroenterology Research and Practice

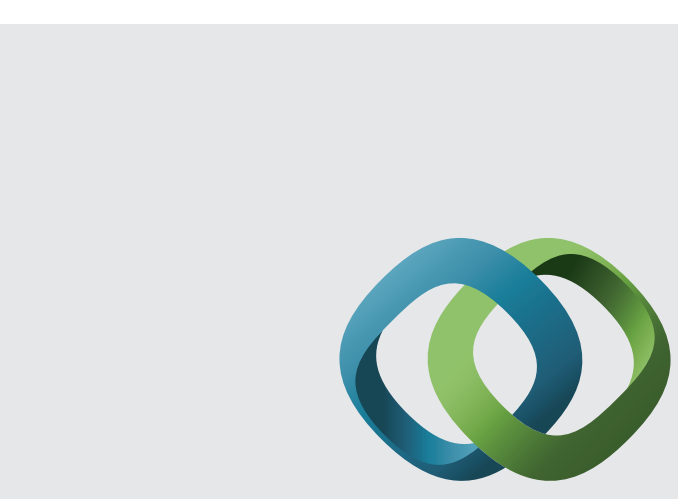

\section{Hindawi}

Submit your manuscripts at

http://www.hindawi.com
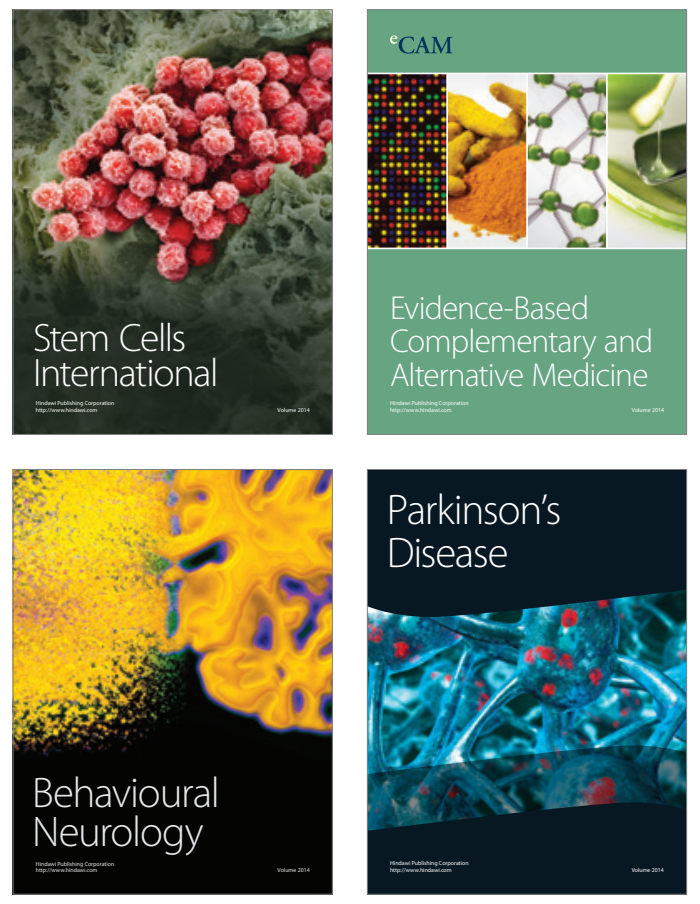
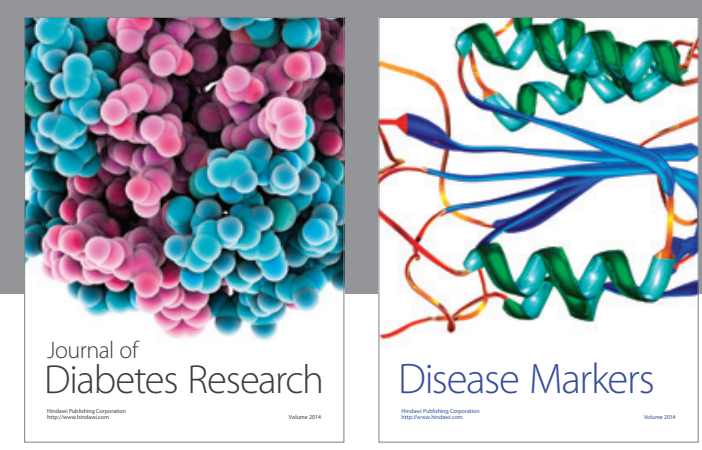

Disease Markers
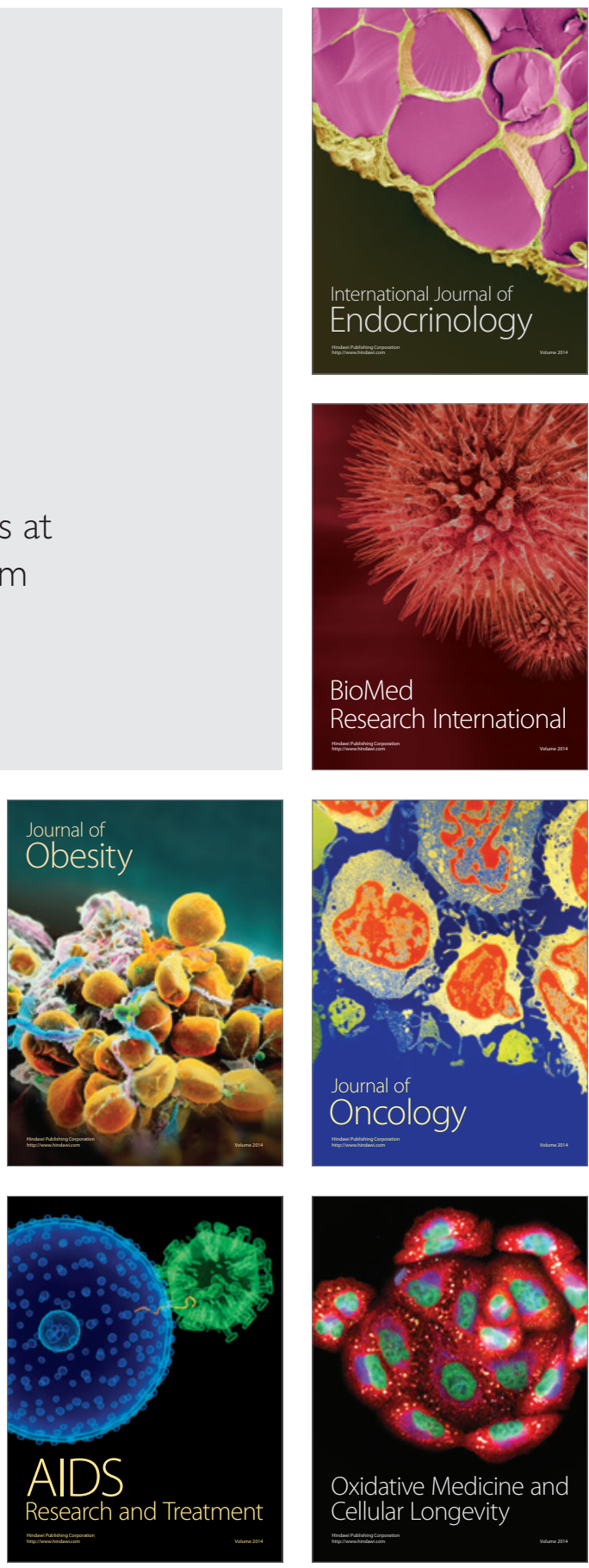